\title{
Ergonomics and Education as a Strategy for Sustainable Development in Business
}

\author{
Dierci Marcio Silveira, PhD.(1), Erico Lourenço Brandão(2) \\ (1)Industrial Systems, Petroleum, Gas and Energy Laboratory - LABSE \\ Industrial and Metallurgical Engineering School \\ Universidade Federal Fluminense-UFF \\ Av. dos Trabalhadores, 420 - Volta Redonda- $R J$ - Brazil \\ CEP 27255-125 \\ e-mail:dsilveira@metal.eeimvr.uff.br
}

\begin{abstract}
It is part of the vocabulary of organizations, and the agendas discussed the subject of "Sustainability", but there are few companies that implement practices or even know the means of implementing sustainable practices. The objective of this paper is to discuss an approach to education for sustainable development (ESD) based on the concepts and practice of ergonomics, as a consequence of this approach allows the implementation of integration initiatives focused on sustainability, such as eg. energy efficiency and consumer awareness thus allowing a means of reducing costs and operating expenses, increased competitiveness and significant contributions to corporate sustainability. There is also the inclusion of sustainability in corporate strategic planning, and their implications in the different spheres of the market.
\end{abstract}

\section{INTRODUCTION}

The discussion of sustainability is real and permeates all the different areas of the market, from basic industry, even outside the organization, down to education. But what is not widespread practice, is the adoption of sustainability as organizational strategy, which by definition shows how committed the company's sustainability. The introduction of the term sustainability has implications on strategic planning at all levels of the organization, and therefore allows the dissemination of the concept and its applications as comprehensively as possible. This diffusion is possible in the organization through the process of education and cultural change in companies and can be implemented through education efforts for sustainable development (ESD) of these policies promoted by the inclusion in strategic planning.
Given that organizations are increasingly implementing corporate education programs to ensure their own survival in the future, the concept of sustainability incorporates the issue of human factors in organizations, as it has been consolidated the belief that the key to its success and its competitive advantage is in offering employees greater access to knowledge and update their qualifications.

The present study aims to present an approach to education for sustainable development, innovation and research of new products and processes designed harmoniously with the concepts of sustainability and the contribution of ergonomics to the formation of human resources engaged in integrative initiatives in organizational environments. It also aligns the goals of this article the concatenation of the concepts of sustainability, corporate education and ergonomics focused on the pressing demands of energy efficiency, consumer awareness and strategic planning in 
order to propose a method for introducing the concepts of sustainability into everyday industrial. Recognizing the critical importance of EDS in the pursuit of sustainability, we should nevertheless bear in mind that both the teaching and training and research are both individual activities - social and collective (resulting from the articulation of individual activities). The forms it takes activity to educate and produce knowledge is not essentially the result of planning processes and prescription. Ergonomics is a scientific definition be dealing with the interaction between humans, the overall performance of the systems environment (IEA, 2000). In view of ergonomics as a discipline which requires multidisciplinary aspect, these processes include the activities and approaches in a broad level to consider the demands that surround sustainability in production environments around.

Also, there is a certain lack of precise and concrete information regarding the adoption of sustainability as organizational strategy, for both the discussion of the matter is still recent, business awareness about the fact that demand is still important advances. But what we see is that there are some pioneers in the study of the strategic agenda with the adoption of sustainability as an integral part of strategic planning.

The concept of sustainability began to be outlined in the UN Conference on the Human Environment in Stockholm in June 1972 was the first major international meeting to discuss the impact of human activities on the environment. But Lester Brown has introduced the concept of sustainability in the 1980s saying: "Sustainability is a process that property as well as continuing to exist in time, it is able to: maintain a standard of quality, provide autonomy maintenance, belong to a network also supporting and promoting sustainable strategies and results in view of the harmony of society-nature relations." From this premise, we established the concept of sustainable development as a way of producing without degrading the environment, so adapting to everyday industrial, arrive at the concept of industrial sustainability, which is a new approach to the strategic process. The concept can also be placed as the interaction between industrial systems and the environment that surrounds them in order to optimize the cycle of inputs. This is the foundation Industrial Environmental Sustainability, the focus of the article does not extend to the social, cultural and political discussion, because it would complicate the analysis
Starting from the premise that strategic planning is the gateway to the design of sustainable production processes, organizational practitioners and employees who embrace the concepts of ergonomics and practices contribute to the planning, product design and operation of these systems and processes and implications generated, marketing, society, competitive advantage and reducing costs. That said, it is clear perspective and focus on what this article intends to address in order to define a method for organizations to raise awareness about the importance of sustainability in its strategic planning. And that the way to accomplish this task is through education and awareness training enabling their employees with respect to environmental sustainability within the area of operation of the organization.

and reduce the focus on inclusion of the concept within the organization's strategic planning. Therefore, the article uses the concept of sustainability solely for education in business, development of training and awareness in sustainability-oriented human factors and environmental impacts.

\section{DESIGN TO EDUCATE AND RAISE AWARENESS}

The way to achieve a significant result of establishment of sustainable culture in the organization is through education. This educational process aims at understanding and awareness of each employee of the organization about what is to be sustainable, and that the organization as a whole represents in the universe. And yet, what individual and organizational attitudes are positive toward the company's transformation into a sustainable organization. In order to educate with the aim of understanding and awareness, you must first understand what is understanding and awareness.

According to the dictionary of the Portuguese language, one of the definitions of consciousness "is that this is a set of ideas, attitudes and beliefs of a group of individuals on what they have in common, and the world around them." And understanding is the stage of knowledge that occurs when the individual appropriates the information (Houaiss, 2001). 
Figure 1 below seeks to clarify the concerns that must be considered in education initiatives focused on sustainability, listing the objectives, scope, approach, criteria and resources to be used. The competencies of ergonomics that contribute to the structuring of a process of education for sustainability includes the areas of organizational ergonomics and their concerns with the optimization of socio-technical systems, ergonomics and cognitive considerations concerning their mental processes as they affect the interactions that take place between humans, making decisions and impacts on the systems and the environment, as well as physical ergonomics in relation to the impacts on safety and health of people and the community with respect to damages to health and comfort conditions related to industrial processes and work.

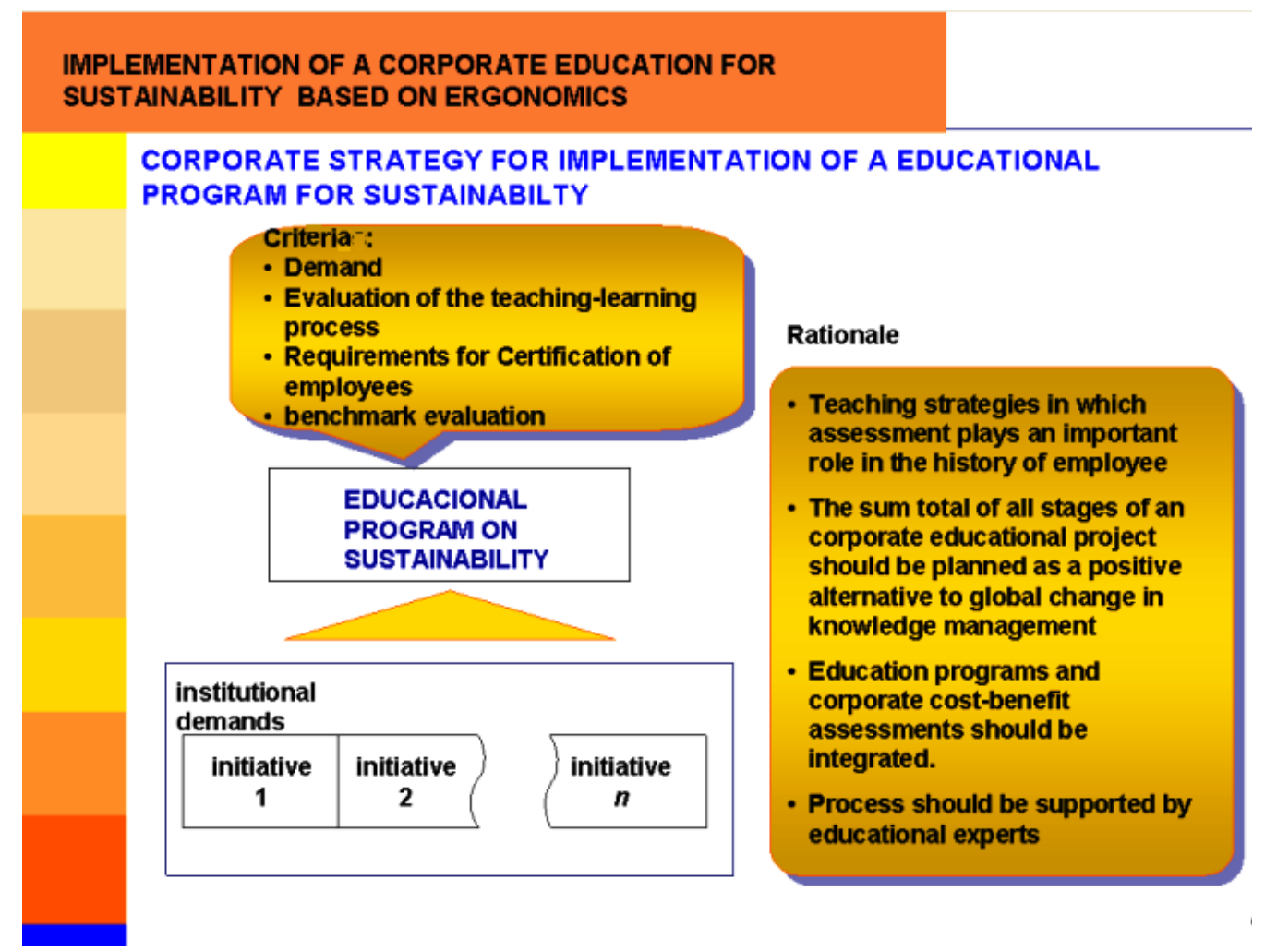

Figure 1 - Assumptions applied in an ergonomics program in Education for Sustainability

Based on these concepts, it is concluded that the aspects related to human factors and ergonomics should be incorporated in the perspective of sustainability, as companies face rapid change in technology, increased expectations about social responsibility and escalating competitive pressures to their products and services. While many labor positions and functions still require manual skills, they also require a greater grounding in how to think and act in a dynamic production environment and ecologically interdependent and need to be updated continuously.

Thus, the initiative in EDS also has the purpose of appropriating them information and then change the ideas, attitudes and beliefs of the group of individuals who form the organization, about the importance of making sustainable organization. Returning to sustainability, this has as one of its paradigms environmental responsibility, so when it comes to understanding and awareness, it is to understand and educate the organization as a whole about their role in initiatives aimed, for example, Energy Efficiency and its impact on the surrounding environment that integrates the company and its production

process.

It is at this point we extend our focus in the practice of environmental responsibility, which is nothing more than the practice of conscious consumption, by 
employees and the study of energy efficiency by the organization. So let's look at what these two activities and how they affect the understanding and awareness of the organization. The basic idea of conscious consumption is to consider it a permanent practice of citizenship, that is, when consumption is consciously goes beyond meeting the individual needs and takes into account the impacts on society, economy and environment (Trigueiro, 2005). Soon, the organization should emphasize that understand consumer awareness and conscious means to appropriate employees of the idea, belief and attitude that citizens involved in the practice of conscious consumption.

While, energy efficiency can be placed, according to ABESCO, "as a technical-economic activity that aims to: provide the best energy and water cost savings, reduce the need for supply of these inputs and input elements and instruments to support energy and water management of the organization. " Therefore, awareness and understanding energy efficiency is aligned with conscious consumption and still be willing to design mechanisms that result in reduced need for inputs, the organizational level. Taking into account these considerations and analysis can now highlight the importance of developing a methodology for corporate education appropriate to implement these ideas of conscious consumption and energy efficiency through education of employees through the process of training and awareness throughout the organization. For example, working from the perspective of technology to reduce consumption by obtaining best practices for energy efficiency, the focus of ergonomics is to hold that employees of the organization preparing to seek possibilities of changing the system of work and production

\section{ENERGY EFFICIENCY, CONSCIOUS COMSUPTION AND OPERATING EXPENSE}

The concept of energy efficiency considered here carries the idea of consumer awareness and implicit cost reduction, along with the idea of continuous improvement with regard to making processes more efficient and productive management of the organization, then highlighting the strategic importance. When a process becomes efficient, the company gains in reducing costs and gains in the use of resources that go back a positive impact on costs, then an energy efficient process is the goal. But, conscious consumption? effectively, where several technical knowledge, operational, about design and maintenance must compete to deploy an ecologically sustainable solution.

\subsection{PARALLEL WITH SAFETY, HEALTH AND ENVIRONMENT}

Parallel to that was put up here, it is noteworthy that this methodology will only be valid if there is support within other methodologies, such as training methods for safety. In fact, there is no single way to implement a safety training within a company, what are guidelines and rules, some of the other government and business that are essential to be worked. So first of all, making the parallel, it is important to analyze the demands of the organization and only then mount the scope of the training.

\subsection{WHAT SHOULD BE DONE?}

Mount the scope of the training based on the requirements of sustainability company-specific, directed to establish standards and organizational practices, to think strategically and based on an ecological perspective, allowing for example, deploy consumer culture and the practice of conscientious study of energy efficiency. How you can make this change in terms of organizational culture? There are several ways to proceed with these actions and an educational training, and the organization should adopt those it deems necessary, which should also be emphasized is that there will never be just a method that meets the organization as a whole, due to various levels of responsibility, education and decision making.

This is part of efficiency, from the time that employees are aligned with the culture of the practice of conscious consumption; the company starts to become energy efficient. Likewise is the operating expense, which, according to Goldratt (1984), "operating expense is all the money the system spends to turn inventory into throughput", so a system is efficient when it spends money only to turn inventory into throughput and not to correct deficiencies in energy supply and consumption of inputs.Now, let's practice. Practicing conscious 
consumption in production, management and society? By definition, the conscious consumption should be viewed as an act of citizenship, so it is the duty of every citizen to be aware as a consumer. However, little is done about it everyday, so in addition to awareness of the attitudes that everyone already knows (brush your teeth with the tap closed, turn off the lights in empty environments, etc.). There are also managerial actions have an impact on higher, how to install sensors on the stairs to avoid excessive light, translucent tiles used in warehouses, to enjoy the light of day, restrict the privileges of the printer within the office only for important documents, and so on.
These management actions listed above, are of major impact, but the adoption of such attitudes has resulted only with proper explanation about the importance of consumer awareness, and this is only achieved through education and awareness of employees, which is aimed precisely at understanding and commitment and to reduce the impact generated by each of these as listed above. Figure 2 below proposes a strategy for implementing a program aimed at education organization focusing on sustainability.

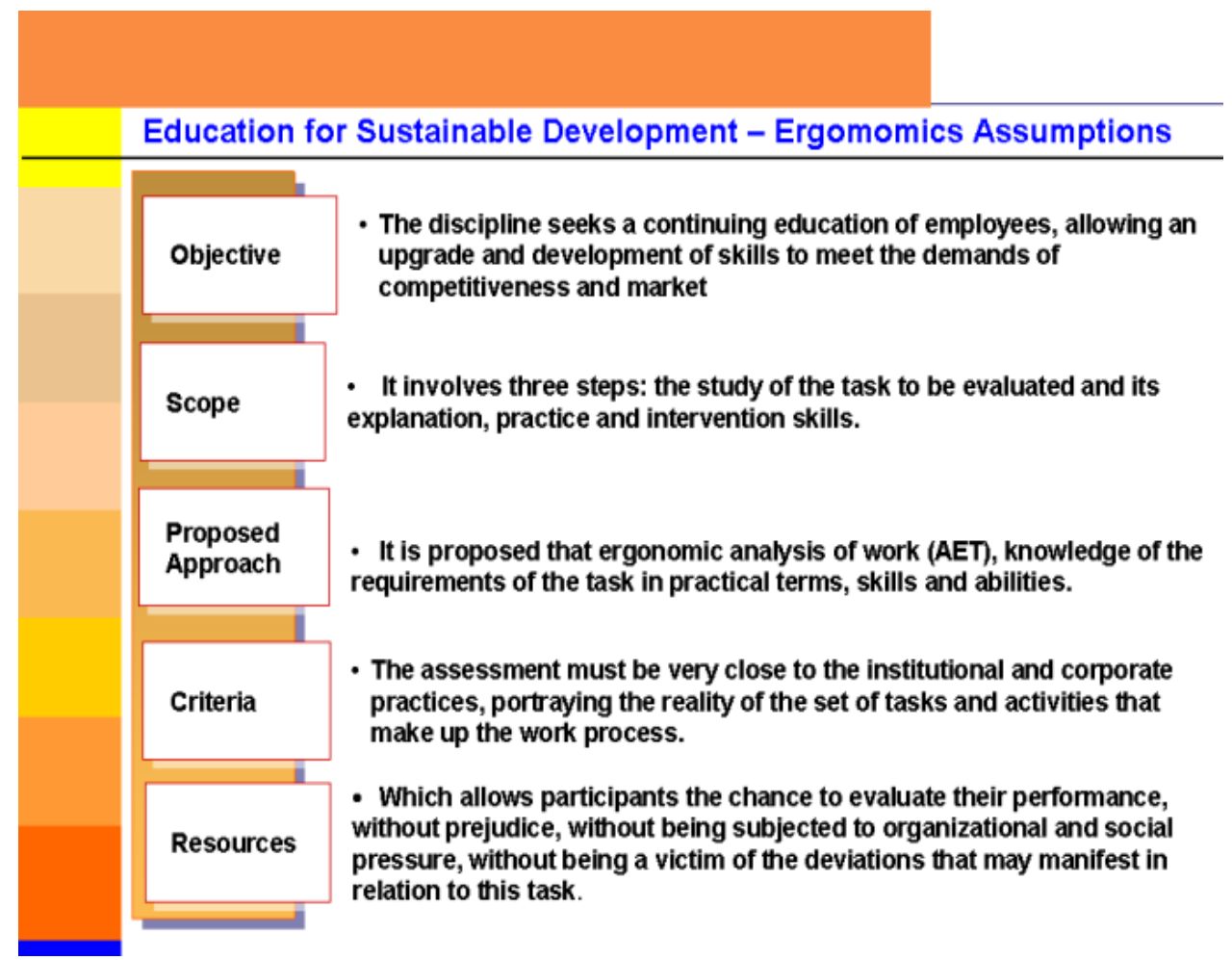

Figure 2 - Strategy for a Program in Education for Sustainability 
As it has been in the management (administration), also it is in society, but to a lesser extent, on a case by case basis. But there is an environment that produces the desired impact throughout society, which is production. The inherent difficulty of introducing tools that are consistent with the policy of consumer awareness, the issue becomes more delicate in the sense that the environment for innovation is by definition an environment that brings uncertainties about the impact of new technologies. But with the proper education with a focus on sustainability and awareness of people involved, one can achieve a very interesting level of awareness and commitment in consumption, which will impact positively on costs and other commitments arising from the process financially and operational why not say those aimed to cover any environmental damage. We can evaluate the importance of awareness and understanding of everyday society these concepts with some examples of Trigueiro (2005), where it is put that: "Although the data are not very accurate, it is estimated that $40 \%$ to $60 \%$ of food produced in Brazil are not leveraged, and $20 \%$ are wasted indoors. The size of the problem is enormous, the loss in Brazil today is 12 billion dollars per year. Would feed 30 million people (is more than we have of undernourished in the country).. " And the example of water: "If 17 million people in the Greater São Paulo turn off the tap when brushing your teeth will save every day, equivalent to the water that falls Iguaçu Falls for nine minutes.." It to show that small gestures, how to plan purchases and close the tap cause a violent impact on the conservation of resources, which is one of the paradigms of sustainability.

\section{STRATEGIC ROLE OF SUSTAINABILITY}

With the understanding that energy efficiency and consumer awareness of sustainability are important variables, we propose to define a model structure of corporate strategic planning inserting the theme of sustainability discussed here. First, it establishes that the method of strategic planning that the article will use is the method of Ansoff, which provides strategic planning variables according to the epistemological dimension, considering the variables first and then the tacit explicit.

For better understanding, let's take a fictitious example of how they fit into the considerations on conscious consumption and energy efficiency within the strategic planning (Chiavenato \& Sapiro, 2009) of any one company.

The first variable is the definition of business, however, regardless of line of business set by the company, sustainability planning will permeate much the same way, so it's not interesting to delve into this topic.

The second variable is the Scenario analysis, since it establishes the way in which the company operates and what precautions it should be, about sustainability, it is feasible to say that when combined with weaknesses in sustainability a strict environmental legislation (threats) the company has a great vulnerability, which can bring many problems in future endeavors. We cite this example only with the intention to illustrate the role of sustainability in strategic planning. The third variable is the mission of the organization, and this defines precisely the reason for the company, then resuming the epistemological dimension of knowledge, we have one of the most important variables of the tacit plan, which is precisely what is the reason for the company. An example would be that the organization's mission is: to operate safely and profitably in the domestic and international efficiency and awareness.

The fourth variable is also implied, is the Vision, it is subordinated to the mission and represents a distant horizon, but achievable by the company and has a deadline. An example would be one of the five largest producers of sugar from Brazil in 2018, ABRAGE increasingly market, safety, efficiency and awareness. The fifth variable is the Principles and Values of the organization, there are contained all the desires of relationships that the company wants, eg: Morals, Ethics (relationship with employees), Honesty and Commitment (relationship with suppliers and customers), Liability (relationship with company), Consciousness (relationship with the environment). It is worth noting that from now on only the variable treats Consciousness as a sum of energy efficiency and consumption. The sixth variable is the company's goals, these are a milestone to be achieved to reach the business, mission, vision, respect the principles and values according to the scenario of the moment. An example of an objective is: To be $100 \%$ energy efficient and be a world class conscious consumer. It is noteworthy that the goal should be considered a utopia and should not have run. 
The seventh variable is the strategy itself, which due to its importance it lends its name to the method, and is nothing more than the necessary means to achieve the goal, so it is an explicit variable. An example would be: Develop technologies that achieve maximum energy efficiency. It also has no running time.

The eighth variable is the goals that are specific milestones to be achieved, are scheduled for completion,

\section{VARIABLE CONSCIOUSNESS}

Consciousness in the context of this study can be placed to represent the sum of energy efficiency and consumer awareness, since both are rooted in culture, and reflect the actions of citizenship, but to clarify the understanding of the issue we turn to another set of consciousness. Consciousness is tacit knowledge about the position of the individual in society and their respective roles (ability to generate impacts) in it. The representation (impact) of each, can be measured as a function of their actions, positive actions generate positive and vice versa. Why do that? To generate data that can be transformed into indicators that show the degree of individual and organizational awareness.

It is noteworthy that the proposed article does not say what the best indicators of performance of consciousness, just speaking about the importance of having them and outline how these could be obtained. A comprehensive numerical index, which represents the actions pro-conscious individual within the organization, the index can take positive and negative values, without considering the impact of the action, taking into account only if it was positive or negative towards consciousness. A numerical index relative character department, relating action and impact, but considering that each fact isolated and its replication in the theme of sustainability. Assuming monetary values of gain or loss, depending on the action taken.

And a percentage index of degree of awareness of organizational character, in order to be compared with the index of other organizations in an attempt to foster the development of pro-conscious. This index relates the two prior to a government standard, to generate the percentage level of the company at the time.

\section{MPLICATIONS GENERATED}

and are derived from goals and strategies. An example would be: train, supervise and reward all employees according to their degree of commitment to conscious consumption until December. The last variable is the Action Plan itself, known to all very simple, the method of $5 \mathrm{~W} 2 \mathrm{H}$, precisely because the latter is stratified goals in order to make timely action, which generates a much higher result.

With this, we are left to consider what implications the adoption of sustainability into the strategic planning can generate, as well as the establishment of indices for comparison of level of organizational awareness is just that while the company is on the path of energy efficiency and conscious consumption.

Consider, first, the implications on cost reduction and operating expense. A building organization that uses solar energy to provide electricity for lighting, refrigeration and basic facilities such as computers and televisions, one saves considerable amount of money, and the investment pays for itself quickly. Considering now the same company that recycles $100 \%$ of the water used in their production processes, consistently fails to pay for the supply of water. Combining these examples with the adoption of more efficient production equipment has been a significant result in the company accounts, just working with energy efficiency and consumption.

Now, about Marketing, has appeal to conscious society, consumers like to know what companies are doing to reduce the environmental impact caused by these same policies, tax incentives to companies who are already reality on the outside, do not delay a lot and they come here. Besides the obvious, which is the company's advertising over the projects of energy efficiency and consumption. Also an important implication, though not often mentioned, which is the competitive advantage that companies gain by adopting this model. By definition, conscious company knows its market position, therefore, knows the best moves, has a larger vision of business, so has a greater competitive advantage.

\section{CONCLUSION}

Gathering all the work put up here, it is expected that the inclusion of sustainability in strategic planning of organizations in the form of variable consciousness, 
in order to encourage the practice of conscious consumption and energy efficiency through an educational process training, and supervision conscientization is a simple task, since all this schematic drawing already exists for other issues such as quality, safety, etc.. But is not giving importance to the fact that the innovation environment is an environment that brings some uncertainties about the impact due to the adoption of new process technologies or developing new products. Any change in the strategic planning involves change in company culture, in particular amendments that result in new perspectives and managerial and organizational positions, and this is a complex change, which requires time, patience and skill in dealing with resistance. A major obstacle that must also be considered is the engagement and commitment from top management, while they do not "embrace" the cause of sustainability, there is nothing you can do. Note also that, by definition, strategic planning can only be changed by top management. Even this is one of the reasons to align sustainability with strategic planning, for when the company is willing to introduce any new concepts in strategic planning, what happens is a change in management culture, which impacts on all spheres of the organization.

Before closing the discussion, it is important to emphasize what can be done today. It is known that consumer awareness is a practice of citizenship, the citizen then he, who in his sovereignty has the full

\section{REFERENCES}

[1] ABESCO, Associação Brasileira das Empresas de Serviços de Conservação de Energia (2011).

http://www.abesco.com.br/siterobot/

Acessed im 30.0ct.2011

[2] Brown, L. (1981). Building a Sustainable Society. 2a Ed.ed. Norton \& Company - New York.

[3] Brutland, G. (1987). Brundtland Report: Our Common Future. World Commission on Environment and Development - UN

[4] Chiavenato, I. Sapiro,A. (2009). Planejamento Estratégico: Da Intenção aos Resultados. $2^{\text {a }}$ Ed.ed. Elsevier - Rio de Janeiro. [5] English, D. (1994). Bioethics: a clinical guide for medical students. New York: Norton, pp. 5-33.

[6] Goldratt, E. (1984). A Meta: Um processo de Aprimoramento Contínuo. $35^{\mathrm{a}}$ Ed.ed. Educator - São Paulo.

[7] Houaiss, A. (2001). Dicionário Houaiss da Língua Portuguesa. $1^{\circ}$ Ed.ed. Objetiva. condition to exercise their creativity to practice conscious consumption. Within the organization, the process can be time consuming, it may be that a small number of people willing to devote to the issue. Yet what is needed is this, start with a group even if reduced, but with a willingness to represent the will of the organization and society to move towards a more balanced world.

Exist today, companies that use renewable energy to provide electricity to their offices, even though the demand for an office is not so great as to a more complex production process. Initiatives as well as reducing the amount of paper used in business is also great, policies used in water recycling processes reduce consumption and thus benefit the businessman who paid a lower account. It is concluded that sustainability is reality and permeates society at all levels, but what you should do is approach it as part of the company's strategy to achieve competitive advantage and market share along with emerging consumers aware. Then the organization you want this slice of the market, should fit the new reality, and there is no more convincing than by educating the employees and the inclusion of sustainability in strategic planning. With these two important tools in the hands of management, coupled with a culture that privileges the human factors and sustainability of the organization in fact, the path to a sustainable industry is well designed for the good of society is clear.

[8] Sachs, I. (2008). Caminhos Para o Desenvolvimento Sustentável. $3^{\text {a }}$ Ed.ed. Garamond - Rio de Janeiro.

[9] Trigueiro, A. (2005). Mundo Sustentável: Abrindo espaço na mídia para um planeta em transformação. $1^{\mathrm{a}}$ Ed.ed. Globo - São Paulo. 